\title{
INVESTIGANDO O CAMPO CONCEITUAL DAS FUNÇÕES: PRIMEIROS RESULTADOS
}

\section{STUDYING THE CONCEPTUAL FIELD OF FUNCTIONS: FIRST RESULTS}

\author{
Clélia Maria Ignatius Nogueira ${ }^{1}$ \\ Veridiana Rezende ${ }^{2}$
}

\begin{abstract}
Resumo: Para o desenvolvimento deste trabalho, partimos do pressuposto que um conceito não pode ser estudado e compreendido isoladamente por meio de uma única situação. Ao contrário, defendemos que são necessárias diferentes situações, diversos conceitos, símbolos, propriedades e teoremas interligados a um mesmo conceito formando um Campo Conceitual. Nesse sentido, fundamentadas na teoria dos Campos Conceituais, e com o olhar voltado para o Campo Conceitual das Funções, o Grupo de Estudos e Pesquisas em Didática da Matemática - GEPEDIMA, que congrega pesquisadores de diferentes universidades estaduais do Paraná, vem desenvolvendo pesquisas com o propósito de explicitar este Campo Conceitual, como identificar e classificar situações matemáticas presentes no Campo Conceitual das funções, bem como "mapear" o processo de construção do conceito de função procurando identificar conhecimentos mobilizados por sujeitos de diferentes idades quando resolvem situações problemas referentes a este campo conceitual. O objetivo deste trabalho é apresentar alguns dos primeiros resultados obtidos pelas investigações realizadas pelo GEPEDIMA.
\end{abstract}

Palavras-chave: Didática da Matemática; Campo Conceitual; Funções.

Abstract: For the development of this work, we start from the assumption that a concept can not be studied and understood alone by means of a single situation. On the contrary, we argue that different situations, different concepts, symbols, properties and theorems interconnected to the same concept forming a Conceptual Field are necessary. In this sense, based on the theory of Conceptual Fields, and looking towards the Conceptual Field of Functions, the Research and Mathematics Didactics Group - GEPEDIMA, which brings together researchers from different state universities of Paraná, has been developing researches with the purpose of to explain this conceptual field, how to identify and classify mathematical situations present in the Conceptual Field of functions, as well as "mapping" the process of construction of the concept of function seeking to identify knowledge mobilized by subjects of different ages when solving situations problems related to this conceptual field. The objective of this work is to present some of the first results obtained by the investigations carried out by GEPEDIMA.

Keywords: Didactics of Mathematics; Conceptual Field; Functions.

\footnotetext{
${ }^{1}$ Doutora em Educação pela Universidade Estadual Paulista Júlio de Mesquita Filho (UNESP). Docente do Programa de Pós-Graduação em Ciências e Educação Matemática (PPGECEM) da Universidade Estadual do Oeste do Paraná (Unioeste), Cascavel, Paraná, Brasil. E-mail: voclelia @ gmail.com

${ }^{2}$ Doutorado em Educação para a Ciência e o Ensino de Matemática pela Universidade Estadual de Maringá (UEM). Docente do Colegiado de Matemática da Universidade Estadual do Paraná (UNESPAR), e do Programa de Pós-Graduação em Ciências e Educação Matemática (PPGECEM) da Universidade Estadual do Oeste do Paraná (Unioeste), Cascavel, Paraná, Brasil. E-mail: rezendeveridiana@gmail.com
} 


\section{Introdução}

O conceito de função é um dos principais da área de Matemática, pois são as funções que dão mobilidade à Matemática, retirando essa ciência de sua rigidez estática, permitindo a representação e o estudo de fenômenos móveis (NOGUEIRA, 2014). A pesquisadora afirma que o ensino de funções ficou restrito, pelo menos até à metade do século XIX, ao Ensino Superior e desde a década de 1960, com o movimento da Matemática Moderna, passou-se a recomendar o ensino desse conceito a partir do que denominamos atualmente como o terceiro ciclo do Ensino Fundamental. Posteriores reformas o conduzem para o primeiro ano do Ensino Médio. No Ensino Superior, diversas áreas e disciplinas (Biologia, Economia, Engenharias, Geografia etc) adotam estudos implícitos ou explícitos, aprofundados ou não, sobre funções.

De acordo com documentos oficiais brasileiros para o ensino de Matemática (BRASIL, 1999; PARANÁ, 2008), o estudo das funções auxilia o aluno na compreensão de fenômenos do cotidiano e no estudo de elementos da Matemática, por meio da leitura, interpretação, construção de gráficos. Além do mais, tanto os PCN - Parâmetros Curriculares Nacionais (BRASIL, 1999) quanto as DCE - Diretrizes Curriculares do Estado do Paraná (PARANÁ, 2008) afirmam que o conceito de função está relacionado a outras áreas do conhecimento como a Física, Geografia, Economia, explicitando a importância de se explorar, na Educação Básica, o estudo das funções juntamente com outras áreas da Ciência.

Segundo os PCN (BRASIL, 1999), a formalização do conceito de função deve ocorrer no Ensino Médio. Contudo, o estudo de noções básicas para a compreensão deste conceito deve iniciar durante a introdução de ideias algébricas desde os Anos Iniciais, a partir da generalização de padrões, estabelecimento de relação e variação de grandezas, modelização, representação de problemas por meio de equações e inequações (diferenciando parâmetros, variáveis, incógnitas, tomando contato com fórmulas), compreendendo a sintaxe (regras para resolução) de uma equação, o que também é recomendado pelo documento mais atual, a Base Nacional Comum Curricular a BNCC que estabelece 16 habilidades necessárias para o ensino da álgebra nos anos iniciais dentre as quais às referentes às ideias de regularidade, inclusive com o estabelecimento de regras de formação de uma sequência (BRASIL, 1998; BRASIL, 1999; BRASIL, 2017).

Compartilhando com o estabelecido por Vergnaud (1990) de que a aprendizagem de um conceito se dá ao longo do processo escolar, em decorrência das diferentes 
situações vivenciadas pelos sujeitos e de que um conceito não pode ser examinado, apreendido, isoladamente sendo necessárias diversas situações para compreendê-lo, este texto tem por objetivo apresentar alguns dos primeiros resultados obtidos pelas investigações realizadas pelo GEPEDIMA relacionadas ao Campo Conceitual das Funções.

Apenas analisando aspectos pertinentes à definição e à representação de uma função é possível intuir o Campo Conceitual de Funções, pois podem ser detectados outros conceitos matemáticos necessários à sua compreensão como "[...] relação entre conjuntos, variação, dependência e correspondência entre variáveis, variável dependente e independente entre outros", além de diferentes formas de representação possíveis, como gráficos, diagrama de flechas, expressão algébrica (OLIVEIRA, 1997, p.8).

Entretanto, Vergnaud (1990) defende que um conceito não pode ser reduzido a sua definição. Esta afirmação não significa que o pesquisador minimize a importância de se definir os conceitos no decorrer de sua aprendizagem, mas que apenas a definição de um conceito não é suficiente para compreendê-lo na essência. Por exemplo, apenas apresentar a definição do conceito de função não é suficiente para que o aluno compreenda o conceito em questão. É preciso ir além da definição formal e da descrição verbal, é preciso considerar a forma simbólica e, sobretudo, as diversas situações relacionadas às funções. Este é o principal objetivo do projeto de pesquisa em desenvolvimento, pois sendo as situações a porta de entrada para a construção do conceito, identificá-las, delimitá-las e tipificá-las é o primeiro passo para a explicitação do Campo Conceitual das Funções.

Outro objetivo do grupo de pesquisadores é "mapear" o processo de construção do conceito de função procurando identificar conhecimentos mobilizados por sujeitos de diferentes idades quando resolvem situações problemas referentes a este campo conceitual, desde alunos da primeira fase do Ensino Fundamental até licenciandos em Matemática e em Pedagogia.

Considerando as pesquisas realizadas no Brasil sobre o ensino de funções baseadas ou não na Teoria dos Campos Conceituais há a necessidade de se estabelecer uma aproximação ao estado da arte, o que se constitui também em um dos objetivos específicos do projeto.

Até o momento temos três investigações concluídas, uma releitura de dados de uma tese já defendida e nove investigações em andamento, além de um projeto de extensão com a participação de professores da Educação Básica e alunos de graduação, 
com realização de atividades de estudo que culminaram em implementação de algumas propostas que estão sendo organizadas para a divulgação em forma de livro.

\section{As primeiras investigações que deram origem às pesquisas sobre o Campo Conceitual das Funções}

Os resultados de duas investigações já concluídas (RORATTO, 2009; PAVAN, 2010), orientadas por uma das integrantes do grupo de pesquisadores foram substanciais para as reflexões que deram origem ao projeto em andamento.

Roratto (2009) assumiu como conjectura inicial que a maneira essencialmente formal, rigorosa, abstrata e dedutiva com que se apresenta a Matemática aos estudantes pode ser um dos fatores que geram uma baixa compreensão dessa matéria, particularmente quando se trata do ensino de funções em que definições na forma final deste conceito constituem, quase sempre, o ponto de partida para seu ensino.

No intuito de propor um ensino que não privilegiasse uma apresentação essencialmente formal e dedutiva do conteúdo de Funções e que visasse ofertar uma aprendizagem contextualizada desse conceito, considerou-se, a possibilidade da História da Matemática, como estratégia para o alcance de tais objetivos.

Mediante o estudo de autores como Boyer (1974), Braga (2003, 2006), Caraça (1984), e Eves (1997), foi então elaborada uma sequência didática em que cada conjunto de situações-problema abordava um conceito-chave que foi importante para o desenvolvimento epistemológico das Funções.

O objetivo era que cada um daqueles conceitos atuassem, pedagogicamente, como conhecimento prévio para o estudo dos conceitos posteriores na sequência didática. Com isso, faríamos o uso de uma das perspectivas do uso da História da Matemática no ensino da Matemática, a perspectiva Evolucionista Linear³ (MIGUEL; MIORIM, 2004).

Tal como ocorreu no desenvolvimento epistemológico, a sequência didática abordou, inicialmente, conceitos que contribuíram para a formalização das Funções, como relações de dependência, representações tabulares, reconhecimento de regularidades, variáveis, representações gráficas, linguagem algébrica e representações analíticas para, finalmente culminar na formalização daquele conceito. Como forma de coleta de dados utilizou-se as respostas das atividades feitas pelos estudantes e Mapas

\footnotetext{
${ }^{3}$ Temos conhecimento das críticas feitas a essa perspectiva do uso da História no ensino de Matemática por autores como Miguel e Miorim (2004), principalmente no que se refere ao tempo despendido em um ensino nesses moldes. No entanto, a pesquisa apontou possibilidades interessantes de seu uso.
} 
Conceituais elaborados pelos aprendizes durante e ao final da aplicação da sequência didática.

A sequência se constituiu de seis atividades compostas por situações-problema com um objetivo em comum. A primeira estava relacionada com o estudo de Relações de Dependência e envolvia duas situações. A segunda e terceira, constituídas por três situações cada, trabalhavam Tabelas e a identificação de Regularidades. Na quarta atividade, três situações objetivavam a identificação de Regularidades e a introdução do conceito de Variável. Na quinta atividade, contando com cinco situações-problema, abordamos as Representações Gráficas de Funções para, por fim, na atividade seis, trabalharmos com a linguagem Algébrica e a representação Analítica de Funções ao longo de quatro situações. A sequência didática foi aplicada em uma turma de nono ano de uma escola pública de um município do norte do Paraná.

Considerando ainda a História da Matemática Roratto (2009), também procurou estabelecer a "gênese artificial" do conceito. Exemplificando: os estudos realizados permitiram identificar que a ideia base de relação de dependência constituiu-se "[...] nos primeiros passos rumo à formalização do conceito de Funções, visto que o universo apresenta dependências e estas interferem diretamente nas questões de sobrevivência do homem", a opção do autor foi por iniciar a sequência didática por questões relacionadas às relações de dependência na própria natureza, como, por exemplo, na cadeia alimentar ou em relação às intempéries da natureza, primeiramente, de forma essencialmente qualitativa, pois, historicamente, de acordo com Caraça (1984) a quantificação se desenvolveu posteriormente ao tratamento qualitativo (RORATTO, 2009, p.71).

As tarefas das atividades aplicadas e validadas por Roratto (2009) subsidiaram a elaboração de instrumento de coletas de informação da pesquisa em andamento e a experiência exitosa com o estabelecimento de uma sequência de atividades para o ensino de função considerando a apresentação das ideias base na ordem constatada pelos estudos históricos, não apenas validaram a importância dessas ideias como apontaram indicativos para o mapeamento da construção do conceito de função, o que motivou a realização da investigação realizada por Pavan (2010), que procurou identificar se se as ideias base de função podem ser mobilizadas já nos anos iniciais do Ensino Fundamental.

Pavan (2010), considerando a importância do conceito de função para a Matemática e para outras áreas e por este campo conceitual abranger ideias básicas que podem (e devem) ser construídas bem antes do $1^{\circ}$ ano do Ensino Médio, se propôs a investigar se situações-problema envolvendo estrutura aditiva ou estrutura multiplicativa 
possibilita às crianças do $5^{\circ}$ ano do Ensino Fundamental reconhecer e mobilizar ideias base envolvidas no conceito de função como, correspondência, variável, dependência, regularidade e generalização. Afinal, de acordo com Moreira (2004, p.38) “[...] o domínio de um campo conceitual ocorre durante longos períodos de tempo, de forma que novos problemas e novas propriedades relacionados com ele devem ser estudados ao longo de vários anos se quisermos que os alunos o dominem progressivamente".

Um fato importante que caracteriza um campo conceitual é que os conceitos a ele pertinentes são construídos de maneira solidária e sincrônica, isto é, ao mesmo tempo em que um se apoia no outro para se construir é também apoio deste outro em sua construção. A investigação realizada por Pavan (2010) permitiu visualizar essa interdependência.

A opção de Pavan (2010) por problemas do Campo Conceitual das Estruturas Multiplicativas se deu pelo fato que este campo é definido como o conjunto das situações que envolve uma ou várias multiplicações ou divisões, o conjunto dos “" [...] conceitos e teoremas que permitem analisar essas situações: proporção simples e proporção múltipla, função linear e n-linear, razão direta e inversa, quociente e produto de dimensões, combinação linear e aplicação linear, fração, número racional, múltiplo e divisor, etc." (VERGNAUD, 1993, p. 10).

Pavan (2010) parte da conjectura de que quando se pretende estudar o processo de elaboração de um conceito, a primeira coisa a ser feita é determinar quais são as ideias base envolvidas. Para a construção do conceito de função, são de fundamental importância as noções de variável, correspondência, dependência, regularidade, e generalização (CARAÇA, 1984; TINOCO, 2002), que são componentes do Campo Conceitual das Funções.

A busca pela mobilização das ideias base de função em tarefas de estruturas multiplicativas é possível em consequência da imbricação entre os Campos Conceituais Multiplicativo e o das funções uma vez que, de acordo com Oliveira (2004), o pensamento multiplicativo envolve implicitamente ou explicitamente a relação de proporcionalidade sendo esta última, outra das ideias fundamentais na construção do conceito de função, conforme estabelecido por Tinoco et al., (2008):

O pensamento proporcional pode contribuir para o desenvolvimento da Álgebra, se for levado em conta que o raciocínio com proporções envolve: senso de co-variação, comparações múltiplas, predição e inferência, que utilizam métodos de pensamento qualitativo e quantitativo, sendo, portanto, uma ponte adequada e necessária entre experiências e modelos numéricos e relações abstratas e genéricas, que se expressarão de forma algébrica, além de ser um exemplo simples, mas importante, de função matemática (TINOCO et al., 2008, p. 3). 
A análise dos resultados de Pavan (2010) possibilitou constatar os diversos esquemas $^{4}$ utilizados pelas crianças na resolução das situações-problema e ainda identificar possíveis teoremas-em-ação investigados a partir das manifestações orais ou gestuais das crianças e pelo registro escrito nas situações-problema. Os resultados comprovaram que os sujeitos da pesquisa reconhecem e mobilizam, ainda que de modo intuitivo, esses elementos indicando que as ideias base envolvidas no conceito de função podem e devem ser trabalhadas já na primeira fase do Ensino Fundamental, para, posteriormente, serem promovidas ampliações do campo conceitual.

Considerando então esses resultados e com vistas a mapear a construção do conceito de função durante o período de escolarização ${ }^{5}$, atualmente já foram coletados dados referentes à mobilização das ideias base de função por estudantes do $9^{\circ}$ ano do Ensino Fundamental; $3^{\circ}$ ano do Ensino Médio e $4^{\circ}$ ano de licenciatura em Matemática e em Pedagogia, cuja análise ainda está em andamento. Até o momento, referente a esta pesquisa sobre a construção do conceito de função durante o período de escolarização, foram analisados os dados relacionados aos alunos do $9^{\circ}$ ano do Ensino Fundamental e $3^{\circ}$ ano do Ensino Médio. Apresentamos a seguir os procedimentos de coleta de dados e os principais resultados relativos a uma das tarefas do instrumento de pesquisa aplicada a estes alunos.

A atividade foi aplicada no próprio Colégio dos alunos, mas em contra turno às suas aulas. Todos os alunos de uma turma de $9^{\circ}$ ano do Ensino Fundamental e de uma turma do $3^{\circ}$ ano do Ensino Médio foram convidados pela professora de Matemática para participarem da pesquisa. Doze (12) alunos aceitaram o convite e foram considerados como sujeitos da pesquisa. Os alunos resolveram individualmente as tarefas aplicadas pela pesquisadora, uma das autoras deste trabalho, com o auxílio da professora de Matemática da turma. A seguir, apresentamos a tarefa proposta aos alunos, seguida das análises principais referente aos dados coletados.

\footnotetext{
${ }^{4}$ Para Vergnaud (1990), um esquema é a totalidade da organização de uma atividade por um sujeito.

${ }^{5}$ Esta parte da pesquisa foi financiada por recursos da Fundação Araucária - Agência de fomento às pesquisas do Estado do Paraná.
} 
Tarefa: $O$ restaurante Rango, cobra $R \$ 3,80$ pelo consumo de $100 \mathrm{~g}$ de comida. Três pessoas foram ao restaurante Rango e cada uma consumiu uma lata de refrigerante que custa $R \$ 3,50$, e as seguintes quantidades de alimentos:

Fabricia consumiu 200g. Fernando consumiu 400g. Lucas consumiu $500 \mathrm{~g}$.

a) Qual o valor pago por cada pessoa? Explique como você determinou cada um desses valores?

b) Na determinação dos valores a serem pagos para cada pessoa, identifique o que varia e o que é fixo.

c) Indique uma expressão matemática que relaciona o peso (p) ao valor a ser pago (V), incluindo o refrigerante.

d) Carla almoçou no restaurante Rango e pagou $R \$ 24,40$ pela refeição com um refrigerante. Quantos gramas de comida Carla consumiu?

Para as nossas análises, consideramos os registros escritos dos alunos. A partir das resoluções e estratégias utilizadas pelos alunos elaboramos quadros (REZENDE; NOGUEIRA; CALADO, 2018, no prelo) contendo as ideias base do conceito de função mobilizadas pelos sujeitos e as diferentes estratégias utilizadas por eles na resolução de cada item das tarefas.

As análises das respostas apresentadas pelos sujeitos mostram suas dificuldades ao resolverem uma tarefa relacionada ao conceito de função afim, considerada relativamente simples para estudantes de $9^{\circ}$ ano do Ensino Fundamental e $3^{\circ}$ ano do Ensino Médio, conforme observa-se no enunciado da tarefa apresetada. Destacamos que dentre os quatro itens respondidos na tarefa pelos 12 alunos, ou seja, dentre as 48 resoluções analisadas, apenas 16 foram consideradas totalmente corretas, 07 foram considerada parcialmente corretas, 15 respostas incorretas, além de 10 ausência de resposta (em branco). E, dentre as 16 respostas corretas, 14 estão associadas aos itens a) e b), e 02 corresponde ao item d). Ou seja, nenhum estudante mobilizou estratégias corretas associadas à ideia base de generalização ao responder a questão c) Indique uma expressão matemática que relaciona o peso ( $p)$ ao valor a ser pago (V), incluindo o refrigerante. Apenas dois (02) estudantes apresentaram estratégias corretas ao responder a questão d) Carla almoçou no restaurante Rango e pagou $R \$ 24,40$ pela refeição com um refrigerante. Quantos gramas de comida Carla consumiu? No caso do item d), associamos também a dificuldade dos alunos em relação à generalização, pois inferimos que se os alunos tivessem acertado a generalização no item c), a quantidade de acertos para o item d) seria maior. Afinal, os alunos que apresentaram resposta correta para o item d) adotaram estratégias de aproximações por tentativa e erro. 
Outro fato que chama atenção relacionado à generalização, item c), é que foram apresentadas 7 respostas em branco, 02 respostas incorretas e 03 estratégias parcialmente corretas. As respostas parcialmente corretas apresentadas pelos alunos foram: i) $\mathrm{V}=3,8 \mathrm{p}$, na qual o aluno EF2 desconsidera o preço do refrigerante; ii) $\mathrm{V}=\mathrm{p}+3,5$, o aluno EM2 desconsidera o preço do quilo da comida; iii) $\mathrm{V}=(\mathrm{g} / 100)$.t.r; sendo que para esta resposta o estudante EM3 explica que $\mathrm{v}$ é o valor total pago, g é a quantidade de gramas consumidas, t a tarifa fixa cobrada a cada 100 gramas, $r$ valor do refrigerante. No entanto, EM3 multiplica o valor do refrigerante ao invés de somá-lo.

Os resultados desta pesquisa mostram que os 12 estudantes da Educação Básica, sujeitos desta pesquisa, que finalizavam o $9^{\circ}$ ano do Ensino Fundamental e o $3^{\circ}$ ano do Ensino Médio apresentam diversas estratégias incorretas para resolução da tarefa proposta sobre função afim. Destacamos o fato que nenhum estudante apresentou estratégia correta para os quatros itens propostos na tarefa. Em relação às ideias base do conceito de função, notamos que os estudantes mobilizaram corretamente as ideias de de variável, dependência e correspondência. A regularidade não foi proposta na tarefa, e a generalização não foi mobilizada corretamente. Além disso, a generalização não foi mobilizada corretamente por nenhum dos estudantes investigados, e que apenas 3 estudantes, sendo 1 do Ensino Fundamental e 2 do Ensino Médio utilizaram estratégia parcialmente correta relacionada à ideia base de generalização, conforme quadros apresentados em Rezende, Nogueira e Calado (2018, no prelo). O fato de a maioria dos estudantes investigados por Rezende, Nogueira e Calado (2018) não mobilizarem à ideia base de generalização tem motivado às pesquisadoras à aprofundarem suas investigações nesta direção com estudantes do $9^{\circ}$ ano do Ensino Fundamental, fato que vem culminado com a dissertação de Mestrado de uma destas autoras, sob orientação das demais.

\section{Investigações atuais que estão sendo realizadas pelo grupo de pesquisadores}

Para evitar sobreposição de investigações, está sendo realizada uma aproximação ao estado da arte. Já foi concluído um estudo acerca dos artigos publicados em periódicos científicos online, da área de Ensino, específicos de Educação Matemática qualificados pela $\mathrm{CAPES}^{6}$, em 2014, com os estratos A1, A2 e B1 da área de Ensino ${ }^{7}$, sobre o tema funções.

\footnotetext{
${ }^{6}$ Coordenação de Aperfeiçoamento de Pessoal de Nível Superior.

${ }^{7}$ Consideramos os qualis2014 dos periódicos entre os meses de agosto e setembro de 2016, conforme dados disponíveis na plataforma Sucupira.
} 
Foram identificados vinte e dois (22) artigos que tratavam do tema em questão e após uma análise prévia foram selecionados dezoito (18) artigos para um estudo detalhado. A escolha foi feita de modo a restringir para os nossos estudos os artigos que tratam apenas de Função Afim e Função Quadrática. Os artigos que tratavam de funções exponenciais e funções trigonométricas, tais como função seno, função cosseno, não foram considerados para os estudos detalhados. Esta opção pelos artigos sobre função afim e quadrática decorre do fato de que as pesquisas do grupo, neste momento, estão voltadas para o Campo Conceitual destas funções.

Diante da diversidade de trabalhos, e considerando seus objetivos de pesquisa, tais pesquisas foram distribuídas em quatro agrupamentos, que tratam do conceito de função nas mesmas direções, são eles:

i. Pesquisas que abordam propostas "diferenciadas" para a sala de aula: dentre os dezoito (18) artigos selecionados, nove (09) referem-se a propostas "diferenciadas" para as aulas de Matemática, acerca do tema funções. Como propostas diferenciadas consideramos aquelas que fogem da abordagem tradicional na qual o professor apresenta o conteúdo, resolve em conjunto com os alunos um ou mais exercícios e propõe aos alunos a resolução de outros exercícios semelhantes àqueles já resolvidos em sala de aula. Dentre os nove (09) artigos que contemplam este agrupamento, foram identificados como propostas diferenciadas aquelas que abordam o conteúdo de função por meio de atividades práticas, diferentes representações do conceito de função, softwares como o GeoGebra e o Winplot, História da Matemática, construção de vídeos pelos alunos, Jogos matemáticos, resolução de problemas, modelagem matemática.

ii. Pesquisas que analisam a elaboração de tarefas sobre o conceito de função, por professores ou futuros professores: diferentemente das demais pesquisas, 02 (duas) se referem a investigar professores ou futuros professores no ato da elaboração de atividades sobre o conceito de função, ou sobre a preparação de uma aula sobre este conceito.

iii. Pesquisas que investigam conhecimentos de professores ou de estudantes sobre o conceito de função: para este agrupamento, consideramos quatro (04) pesquisas dentre as analisadas. Estas pesquisas se propõem a investigar conhecimentos de professores ou de estudantes acerca do conceito de função.

iv. Pesquisas que se referem a estudos bibliográficos ou análises de livros didáticos. Nossos estudos apontaram três (03) pesquisas relacionadas a este agrupamento. 
As pesquisas identificadas bem como os quatro (04) agrupamentos estabelecidos, permitem direcionar e fundamentar as investigações do grupo referente ao Campo Conceitual das funções. Atualmente, estão sendo realizadas buscas no banco de teses da CAPES, e outras fontes de dados como Google Acadêmico, Anais de Eventos Científicos de Educação Matemática, páginas de Programas de Pós-Graduação e outras fontes.

Uma outra pesquisa que vem sendo realizada por um dos integrantes do GEPEDIMA, orientado pelas autoras deste trabalho, tem como objetivo principal caracterizar e categorizar situações-problemas relacionadas ao conceito de função afim, à luz da teoria dos Campos Conceituais. Com a intenção de determinar uma tipologia para as situações, tomamos como base para as análises os critérios estabelecidos por Gérard Vergnaud para a classificação de situações presentes nos Campos Conceituais Aditivo e Multiplicativo. Fazem parte desses critérios os tipos de relações (binárias, ternárias e quaternárias) estabelecidas entre os elementos presentes nos problemas e os tipos de situações dos Campos Conceituais Aditivo e Multiplicativo.

Como fonte de dados para a análise das situações-problema adotamos Livros Didáticos de Matemática do $1^{\circ}$ ano Ensino Médio, aprovados pelo Programa Nacional do Livro Didático - PNLD 2018. Até o momento, fizemos uma estimativa de analisar as situações-problema de duas a três coleções de Livros Didáticos de Matemática, considerando as coleções mais adotadas nos colégios públicos da região de Campo Mourão - Paraná. A análise se restringe ao capítulo específico do conteúdo de função afim, com foco nas situações-problema presentes nos livros analisados.

As análises prévias realizadas até o momento se referem a cinco situaçõesproblema presentes no Livro Didático de Matemática do $1^{\circ}$ ano do Ensino Médio mais adotado na região de Campo Mourão, apresentadas na introdução ao conteúdo de função afim e em exemplos resolvidos desta obra. As análises parciais nos revelaram que as situações-problema relacionadas ao conceito de função afim podem ser analisadas com base nas Estruturas Aditivas e Multiplicativas, sendo parte das situações-problema consideradas restritamente do campo multiplicativo, do tipo isomorfismo de medidas e outras consideradas mistas, pois identificamos que se tratam de combinações de problemas das Estruturas Multiplicativas (isomorfismo de medidas ou proporção simples) e das Estruturas Aditivas (composição de medidas e de transformação).

Para melhor compreensão das análises realizadas até o momento, destacamos a análise da uma situação-problema identificada no Livro Didático, utilizada na introdução 
ao conteúdo de função afim. A investigação apresentada a seguir é referente à pesquisa que vem sendo realizada por Miranda (2018, no prelo)

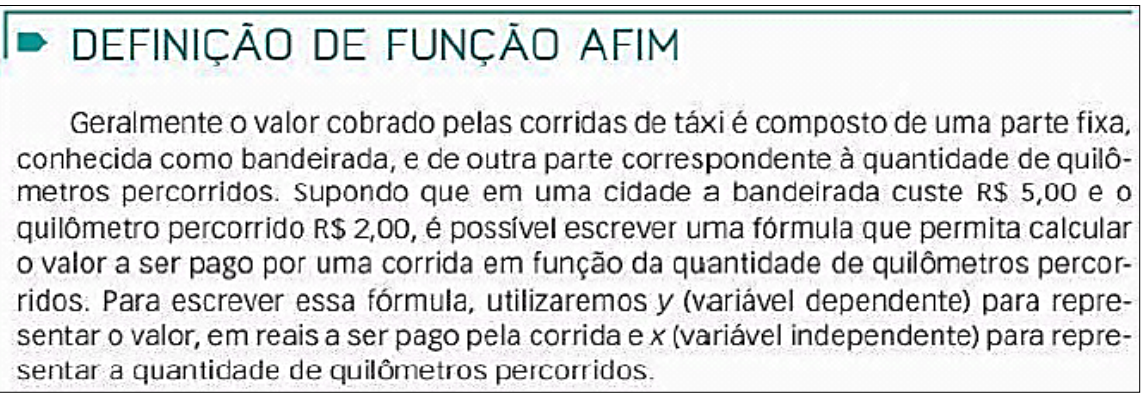

Figura 1: Problema introdutório de função afim Fonte: Balestri (2016, p. 68)

A representação a seguir, baseada em Vergnaud (2009), permite uma análise detalhada das informações e perguntas pertinentes à situação e das relações estabelecidas entre os elementos presentes nas situações problemas.

\begin{tabular}{|c|c|c|c|c|}
\hline & $\begin{array}{l}\text { Distância percorrida } \\
\qquad(\mathrm{Km})\end{array}$ & $\begin{array}{c}\text { Valor } \\
\text { correspondente aos } \\
\text { quilômetros } \\
\text { percorridos }\end{array}$ & Valor da taxa fixa & \multirow[t]{2}{*}{ Total a pagar } \\
\hline & 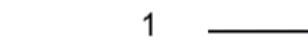 & $\longrightarrow$ & & \\
\hline & $x$ & $\mathrm{~V}$ & 5 & Y \\
\hline $\mathrm{X}$ & \multicolumn{4}{|c|}{ Distância variável de quilômetros percorridos } \\
\hline V & \multicolumn{4}{|c|}{ Valor correspondente a $\mathrm{X}$ quilômetros percorridos } \\
\hline $\begin{array}{l}Y \\
p \in\end{array}$ & \multicolumn{4}{|c|}{ Valor total a ser pago em uma corrida de táxi (Total = valor correspondente aos quilômetros } \\
\hline
\end{tabular}

Figura 2: Organização do problema

Fonte: Dos autores

Considerando a organização proposta anteriormente, nas duas primeiras colunas percebemos uma correspondência de conjuntos de natureza distinta, ou seja, trata-se de uma relação quaternária, de um problema do campo multiplicativo.

Podemos escrever a relação:

Distância Percorrida (Km)

Valor correspondente
1

Em que uma formulação possível é que $1 \mathrm{Km}$ está para $\mathrm{X} \mathrm{Km}$, assim como 2 reais está para $\mathrm{V}$ reais.

$$
\begin{gathered}
\frac{1}{X}=\frac{2}{V} \\
V=2 X
\end{gathered}
$$


A segunda e última relação que se deve considerar é a relação total a pagar, que se trata da composição de duas medidas de mesma natureza (reais), total a pagar = valor correspondente aos quilômetros percorridos + taxa fixa. Entendemos que se trata de um problema de composição do campo aditivo que pode ser escrito por:

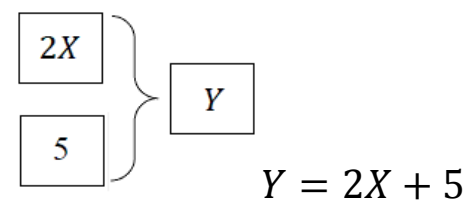

Assim, a situação-problema analisada se trata de um problema misto, pois há uma relação multiplicativa quando temos por objetivo obter o valor a ser pago de acordo com os quilômetros percorridos, neste caso um problema de isomorfismo de medidas ${ }^{8}$ e uma relação aditiva, de composição, quando definimos o total a ser pago, composta pelo valor que depende dos quilômetros percorridos mais a taxa fixa, sendo estes últimos valores em dinheiro a serem juntados.

Consideramos esta pesquisa como marco inicial para a determinação dos diferentes tipos de situações presentes no Campo Conceitual das funções. Levando em consideração a amplitude do Campo Conceitual das funções, neste primeiro momento nos restringimos ao estudo das situações sobre função afim presentes em livros didáticos de Matemática. Juntamente com esta análise das diferentes situações serão investigadas as diferentes representações e símbolos necessários para a compreensão do conceito de função, presentes nas obras analisadas (MIRANDA; REZENDE; NOGUEIRA, 2018, no prelo).

\section{Uma releitura de dados considerando o Campo Conceitual das Funções}

Para Vergnaud (1990), um conceito está em constante aprimoramento, sendo compreendido pelos sujeitos no decorrer da experiência escolar, e em função das diferentes situações que lhes são propostas. Com este pressuposto, uma das autoras deste trabalho, orientada pela outra realizou sua tese de doutorado, que intencionava identificar e analisar conhecimentos mobilizados por estudantes brasileiros e franceses relacionados ao conceito de números irracionais.

\footnotetext{
${ }^{8}$ Miranda (2018, no prelo) apresenta todas as classes de situações propostas por Vergnaud no que diz respeito aos Campos Aditivo e Multiplicativo.
} 
Inspiradas em Douady (1986, 2011), e levando em conta as possíveis imbricações entre Campos Conceituais (TELES; BELLEMAIN, 2013), revisitamos os dados da pesquisa (REZENDE, 2013) relacionados aos dados de quatro situações matemáticas contempladas na tese, relacionadas a medidas de áreas de quadrados, medidas de áreas de retângulos, e equações do $2^{\circ}$ grau. Em função da restrição de páginas, apresentamos a releitura de apenas uma tarefa. Os sujeitos da pesquisa foram 42 estudantes brasileiros e franceses, que finalizavam o Ensino Fundamental, Ensino Médio e Superior de Matemática, e respectivos níveis de ensino francês. A coleta de dados ocorreu por meio de entrevistas semiestruturadas, individuais, com tarefas matemáticas para os estudantes resolverem e dialogarem sobre elas.

Apresentamos a seguir as quatro tarefas cujas respostas dos sujeitos da pesquisa foram analisadas para este texto com o olhar para as ideias base de função. Estas foram as tarefas de ordem 4, 5, 6 e 7 do instrumento de pesquisa (REZENDE, 2013).

Tarefa 1: Existe ou não solução para as seguintes equações: a) $x^{2}=16$; b) $x^{2}=17$; c) $x^{2}=\pi$ ? Em caso positivo, apresente as soluções.

Tarefa 2: a) Existe ou não um quadrado de medida de área $25 \mathrm{~cm}^{2}$ ? Em caso positivo, indique a medida do lado dos quadrados.

b) Existe ou não um quadrado de medida de área $13 \mathrm{~cm}^{2}$ ? Em caso positivo, indique a medida do lado do quadrado.

Tarefa 3: A área do quadrado ABCD é $13 \mathrm{~cm}^{2}$ ? Você concorda com esta afirmação?

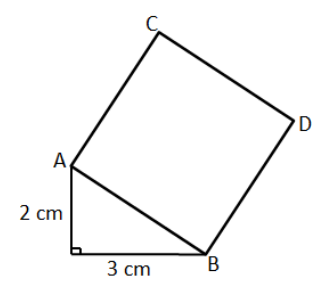

Tarefa 4: a) Represente no $1^{\circ}$ quadrante do plano cartesiano diferentes retângulos cuja medida de área é $24 \mathrm{~cm}^{2}$, de modo que cada retângulo atenda as seguintes condições: tenha um vértice na origem do plano cartesiano, um vértice sobre o eixo x e um vértice sobre o eixo $y$.

b) Além destes retângulos representados, existem outros retângulos como esses (nas condições dadas), que também possuem medida de área $24 \mathrm{~cm}^{2}$ ? Justifique a sua resposta. 
c) Pinte os pontos de coordenadas $(x, y)$ que são vértices dos retângulos de área $24 \mathrm{~cm}^{2}$, e que não pertença aos eixos do plano cartesiano. O que você observa sobre o comportamento destes pontos?

d) Dentre os retângulos possíveis de serem representados, é possível identificar (ou representar) um quadrado neste mesmo plano cartesiano com as mesmas propriedades destes retângulos: um vértice na origem e outros dois sobre os eixos coordenados, e que tenha medida de área igual a $24 \mathrm{~cm}^{2}$ ? Justifique sua resposta.

Informamos que o foco das análises para este texto é a tarefa 4. Esta opção decorre do fato que nela as cinco ideias base de funções (variável, correspondência, dependência, regularidade e generalização) são abordadas implicitamente. Além disso, alguns sujeitos da pesquisa, mesmo tendo indicado a desestabilização de conhecimentos errôneos, relacionados a existência de solução para equações do segundo grau e existência de quadrados em tarefas anteriores, ao resolveram a tarefa 4 voltaram a mobilizar conhecimentos equivocados.

As análises das respostas dos sujeitos da pesquisa mostram que quando se trata de números quadrados perfeitos, no caso os números 16 e 25, os alunos respondem prontamente que a solução da equação $x^{2}=16$ é 4 ou -4 (em alguns casos, principalmente no Ensino Fundamental, o número -4 não é dado como solução). O mesmo ocorre para a medida de lado do quadrado de área $25 \mathrm{~cm}^{2}$, todos os sujeitos da pesquisa responderam prontamente que a medida do lado do quadrado é $5 \mathrm{~cm}$.

Contudo, o mesmo não ocorre para números que não são quadrados perfeitos. Dentre os 30 estudantes da Educação Básica apenas três responderam corretamente sobre a existência de solução para as equações $x^{2}=17$ e $x^{2}=\pi$, apresentando tanto as respostas positivas $(\sqrt{17}$ e $\sqrt{\pi})$ quanto negativas $(-\sqrt{17}$ e $-\sqrt{\pi})$. Outros Quatro estudantes afirmaram que os números $\sqrt{17}$ e $\sqrt{\pi}$ são solução para as equações $x^{2}=17$ e $x^{2}=\pi$, mas são mencionaram as soluções negativas das equações. Os demais alunos alegaram que estas equações não possuem solução, ou apresentaram o número decimal exibido pela calculadora. Com estas respostas, os estudantes indicaram a mobilização dos 
Teoremas em ação ${ }^{9}$ falsos: 1) Se $p \in R_{+}$não é quadrado perfeito então não existe $x \in R$ tal que $x^{2}=p$; e 2) Se $p \in R_{+}$então $x^{2}=p$ tem solução real, dada por $x=\sqrt{p}$.

Em relação à existência de um quadrado de medida de lado $13 \mathrm{~cm}^{2}$, e identificar a medida de seu lado, apenas três alunos da Educação Básica responderam corretamente dizendo que existe o quadrado de medida de lado $\sqrt{13} \mathrm{~cm}$, indicando a mobilização de dois Teoremas em ação falsos: 3) Se $b \in R_{+}$não é quadrado perfeito, então não existe um quadrado cuja medida de área é $A=b \mathrm{~cm}^{2}$; e 4) Seja $a \in R_{+}, \sqrt{a}$ existe se e somente se $a$ é quadrado perfeito.

Considerando que para determinar o lado de um quadrado basta resolver a equação $x^{2}=13$, se os alunos utilizassem o conceito de função quadrática $f(x)=x^{2}$, sua continuidade no conjunto dos números reais e as ideias base do conceito de função muitos dos equívocos cometidos teriam sido evitados para a resolução das tarefas 1 e 2 .

Com a tarefa 3 tivemos a intenção de proporcionar aos alunos reflexões sobre seus próprios erros, e sobre a existência de um quadrado de medida de lados irracional. Dentre os alunos da Educação Básica que resolveram a tarefa 3, quatro (04) afirmaram que existe um quadrado de área $13 \mathrm{~cm}^{2}$, e que seu lado mede $\sqrt{13} \mathrm{~cm}$, indicando a possibilidade de desestabilizar os teoremas em ação falsos mobilizados na tarefa 2.

Já a tarefa 4 apresenta variações de certas medidas em função de outras, ou seja, a variação da medida de um dos lados (pertencente ao eixo y) em função da medida de outro lados (pertencente ao eixo x) do retângulo, mantendo fixa a área destes retângulos, de maneira que o conceito de função, mesmo que não explicitado como objeto matemático, pode ser utilizado como ferramenta implícita que possibilitasse a resolução da tarefa.

Além disso, a tarefa ${ }^{10}$ diz respeito a infinitos retângulos com medida de área $24 \mathrm{~cm}^{2}$, que podem ser representados no plano cartesiano, sob as seguintes condições: os retângulos são representados no primeiro quadrante, um de seus vértices pertence ao eixo $\mathrm{y}$, um dos vértices é a origem, um dos vértices pertence ao eixo x, e o quarto vértice

\footnotetext{
${ }^{9}$ Para Vergnaud (1990), um teorema em ação é uma categoria de conhecimento mobilizado pelo sujeito na ação, podendo ser verdadeiro ou não.

Observação: Para a resolução da tarefa pelos alunos, foram disponibilizado papel milimetrado e/ou representações de alguns retângulos em plano cartesiano.
} 
pertence a uma curva contínua, representada pela seguinte função: $f: R_{+}^{*} \rightarrow R_{+}^{*}, f(x)=$ $\frac{24}{x}$.

Especificamente em relação ao conceito de função, mesmo que contemplado implicitamente, esta tarefa permite aos alunos mobilizar ideias base de função:

i. Variável: os lados dos infinitos retângulos são variáveis.

ii. Dependência: a medida dos lados dos retângulos pertencentes ao eixo $y$ dependem da medida dos lados dos retângulos pertencentes ao eixo $x$.

iii. Correspondência: todo $x$ pertencente $R_{+}^{*}$ (domínio) corresponde a um único $y$ pertencente a $R_{+}^{*}$ (imagem).

iv. Regularidade: ao variar os valores de $x \in R_{+}^{*}$ (um dos lados do quadrado), percebe-se uma regularidade para os valores assumidos no eixo $y$ (lado do retângulo), exemplo:

\begin{tabular}{|c|c|c|c|c|c|c|c|}
\hline$x$ & $\frac{1}{3}$ & $\frac{1}{2}$ & 1 & 2 & 3 & 4 & $\sqrt{24}$ \\
\hline$y$ & 72 & 48 & 24 & 12 & 8 & 6 & $\sqrt{2} 2$ \\
\hline
\end{tabular}

v. Generalização: a partir da regularidade é possível identificar uma representação genérica dada pela expressão algébrica: $y=\frac{24}{x}$.

Além destas ideias base, para o conceito de função esta tarefa permite explorar os conceitos de domínio, imagem, contradomínio, crescimento, decrescimento, continuidade de uma função, teorema do valor intermediário entre outros.

Dentre os 30 alunos da Educação Básica, sujeitos da pesquisa, apenas dois alunos, responderam corretamente que é possível representar um quadrado dentre os retângulos nas condições dadas, indicando como medida de seus lados $\sqrt{24} \mathrm{~cm}$. Os demais alunos ou disseram que não existe o quadrado de medida de área $24 \mathrm{~cm}^{2}$ ou que existe um quadrado de área aproximadamente igual a $24 \mathrm{~cm}^{2}$, conforme fala de um aluno: Só se for um número que não é inteiro. [...] Só se for quatro e alguma coisa vezes quatro e alguma coisa, porque se for 5 dá 25. [...] Ele estaria por aqui, perto de 4,8, perto de 5. Estes dados indicam que os estudantes não perceberam duas das principais ideias base de função: que os lados do retângulo são variáveis e que existe uma relação de dependência entre essas variáveis. Esta percepção teria favorecido a resolução da tarefa.

No que se refere aos alunos do Ensino Superior, dentre os doze entrevistados, três afirmaram sobre a existência de um quadrado de medida de área aproximadamente igual 
a $24 \mathrm{~cm}^{2}$, e os demais, mesmo apresentando algumas dúvidas durante suas resoluções, afirmaram sobre a existência do quadrado, apresentando $\sqrt{24} \mathrm{~cm}$ como medida de seu lado. A resposta de um aluno brasileiro do Ensino Superior, justifica nossa afirmação de que o conhecimento sobre o conceito de função pode colaborar para o sucesso nesta tarefa proposta:

Sim, podemos obter um quadrado com esta área. Usando a curva representada pelos pontos do item (a), podemos usar a propriedade geométrica que todo quadrado é um retângulo, e pode-se afirmar que este quadrado terá o lado aproximadamente entre 4 e 5 , bem próximo de 5 , obtendo um ponto comum à curva $(G 1)$.

Desse modo, notamos que embora o estudante não mencione explicitamente o termo função, ele mobilizou ideias relacionadas a este conceito, pois além de perceber o comportamento contínuo da curva, ele mobilizou as ideias de correspondência (um ponto do domínio corresponde a um ponto da imagem), dependência (a medida do lado do retângulo pertencente ao eixo y depende da medida do lado do retângulo pertencente ao eixo x), variável (no momento que afirma que o lado do quadrado vai estar entre 4 e 5).

É fato que na tarefa acima discutida o conceito de função não é explícito, ou seja, ele não é o objeto do saber desta tarefa, ele é abordado implicitamente e serve como ferramenta (DOUADY, 2011) para que os alunos possam ter sucesso ao resolver a tarefa, o que fica claro na resposta do aluno de graduação G1: pode-se afirmar que este quadrado terá o lado aproximadamente entre 4 e 5, bem próximo de 5 , obtendo um ponto comum à curva, que mobiliza implicitamente ideias base de função: variável, correspondência, dependência.

De acordo com Franchi (2008), o

[...] funcionamento cognitivo do sujeito repousa sobre os conhecimentos anteriormente formados; ao mesmo tempo, o sujeito incorpora novos aspectos a esses conhecimentos, desenvolvendo competências cada vez mais complexas (FRANCHI, 2008, p. 191-192).

Considerando que as ideias base de função e mesmo a definição formal deste objeto matemático já deviam ter sido estudados pelos sujeitos da pesquisa, tendo em vista o nível de escolaridade em questão, os dados analisados nos fazem refletir sobre a possibilidade de os alunos da Educação Básica entrevistados, bem como 3 alunos de graduação, não apresentarem conhecimentos coerentes acerca das ideias base de função que os levassem ao sucesso da tarefa. 


\section{Conclusões}

Com os relatos das diferentes investigações apresentadas neste trabalho pudemos comprovar pressupostos importantes quando se pretende estabelecer o Campo Conceitual das Funções, a saber, que as ideias base podem ser desenvolvidas de maneira informal, desde muito cedo (PAVAN, 2010); que a proposta de tarefas envolvendo as ideias base de função favorecem o aprendizado dos alunos (RORATTO, 2009); que, um conceito demanda muito tempo para ser construído, o que se depreende do fato de que dentre 30 estudantes brasileiros e franceses da Educação Básica instados a responder se "existe um quadrado de área aproximadamente igual a $24 \mathrm{~cm}^{2}$ " apenas dois indicam mobilizar conhecimentos relativos a função.

Além disso, apesar de pesquisadores se referirem ao Campo Conceitual das Funções, como Oliveira (1997), o primeiro estudo sobre pesquisas publicadas em periódicos demonstrou que ainda é preciso um longo caminho de pesquisa para nos permitir explicitar este campo. As investigações em andamento pelo grupo buscam agora a tipificação e delimitação das situações deste Campo Conceitual, tendo como ponto de partida as situações estabelecidas por Vergnaud (1993) para o Campo Conceitual das Estruturas Multiplicativas, considerando as imbricações (TELES, BELLEMAIN, 2013) entre os dois campos, comprovadas por Pavanello e Nogueira (2010).

\section{Referências}

BOYER, C. B. História da Matemática. São Paulo: Edgard Blücher, 1974.

BRAGA, C. O processo inicial de disciplinarização de função no ensino secundário brasileiro. 2003. 117f. Dissertação (Mestrado em Educação Matemática) - Pontifícia Universidade Católica de São Paulo, São Paulo, 2003.

BRAGA, C. Função: a alma do ensino da Matemática. São Paulo: Anablume, 2006.

BRASIL. Ministério da Educação. Secretaria de Educação Média e Tecnológica. Parâmetros Curriculares Nacionais para o Ensino Médio, Brasília, 1999.

BRASIL. Ministério da Educação. Secretaria de Educação. Parâmetros Curriculares Nacionais: Matemática, Brasília, 1998.

BRASIL. Ministério da Educação. Base Nacional Curricular Comum: Matemática. Brasília, 2017.

CARAÇA, B. J. Conceitos fundamentais da Matemática. Lisboa: Livraria Sá da Costa Editora, 1984. 
DOUADY, R. Jeux de cadres et dialectique outil-objet. Recherches en Didactique des Mathématiques, Grenoble, v. 7, n. 2, p. 5-31, 1986.

EVES, H. Introdução a história da matemática. Tradução de Hygino H. Domingues. Campinas: Editora da Unicamp, 1997.

FRANCHI, A. Considerações sobre a teoria dos campos conceituais. In: MACHADO, S. D. A. (Org.). Educação Matemática: uma (nova) introdução. 3. ed. São Paulo: EDUC, 2008. s.p.

MIGUEL, A; MIORIM, M, A. História na Educação Matemática: propostas e desafios. Belo Horizonte: Autêntica, 2004.

MIRANDA, C. A. Uma análise de situações-problemas relacionadas ao conceito de função afim à luz da teoria dos campos conceituais. In: ENCONTRO BRASILEIRO DE ESTUDANTES DE PÓS GRADUAÇÃO EM EDUCAÇÃO MATEMÁTICA, 22, 2018. Belo Horizonte. Anais... Belo Horizonte: UFMG, 2018. (no prelo).

MIRANDA, C. A., REZENDE, V., NOGUEIRA, C. M. I. Uma análise de situações relacionadas ao conceito de função afim na perspectiva da teoria dos campos conceituais. In: SIMPÓSIO DE ENSINO E APRENDIZAGEM, 4, 2018. Londrina. Anais... Londrina, UTFPR, 2018. (no prelo).

MOREIRA, M. A. A teoria dos campos conceituais, o ensino de Ciências e a pesquisa nesta área. Porto Alegre: Instituto de Física da UFRGS, 2004.

NOGUEIRA, C. M. I. Construindo o conceito de funções. In: RAMOS, A.S.; REJANI, F.C. Teoria e Prática de Funções. Maringá: Centro Universitário de Maringá. Núcleo de Educação a Distância, 2014. s.p.

OLIVEIRA, N. de. Conceito de função: uma abordagem do processo ensino-aprendizagem. S.f. 1997. Dissertação (Mestrado em Ensino de Matemática) - Pontifícia Universidade Católica de São Paulo, São Paulo, São Paulo, 1997.

OLIVEIRA, C. A. V. Relações lógicas estabelecidas por alunos de uma quarta série do ensino fundamental. 2004. 93f. Dissertação (Mestrado em Educação Matemática) - Pontifícia Universidade Católica de São Paulo, São Paulo, 2004.

PARANÁ, Diretrizes Curriculares de Matemática para as séries finais do Ensino Fundamental e para o Ensino Médio. Curitiba: SEED, 2008.

PAVAN, L. R. A Mobilização das Ideias Básicas do Conceito de Função por crianças da $4^{\text {a }}$ série do Ensino Fundamental em Situações-Problema de Estruturas Aditivas e/ou Multiplicativas. S.f. 2010. Dissertação (Mestrado em Educação para a Ciência e Matemática) Universidade Estadual de Maringá, Maringá, 2010.

PAVANELLO, R. M.; NOGUEIRA, C. M. I. Aspectos didático-pedagógicos da aprendizagem de áreas e perímetros emergentes de resultados de um estudo investigativo. In: ENCONTRO NACIONAL DE EDUCAÇÃO MATEMÁTICA, 10, 2010, Salvador. Anais... Salvador: SBEM, 2010.

REZENDE, V., NOGUEIRA, C. M. I., CALADO, T. V. Ideias base sobre sobre função afim mobilizadas por estudantes da Educação Básica. In: CONFERENCIA INTERAMERICANA DE EDUCACIÓN MATEMÁTICA - CIAEM, 15, 2019. Mendelin. Anais... Medelín, 2019 (no prelo). 
REZENDE, V. Conhecimentos sobre números irracionais mobilizados por alunos brasileiros e franceses: um estudo com alunos concluintes de três níveis de ensino. s.f. 2013. Tese (Doutorado em Educação para a Ciência e o Ensino de Matemática) - Universidade Estadual de Maringá, Maringá, 2013.

RORATTO, C. A história da matemática como estratégia para o alcance da aprendizagem significativa do conceito de função. 199f. 2009. Dissertação (Mestrado em Educação para a Ciência e a Matemática) - Centro de Ciências Exatas, Universidade Estadual de Maringá, Maringá, 2009.

VERGNAUD, G. La théorie des champs conceptuels. Recherche en Didactique des Mathématiques, Grenoble, v. 10, n. 2.3, p. 133-170, 1990.

VERGNAUD, G. Teoria dos campos conceituais. CRS e Université René Descartes. Palestra proferida no I Seminário Internacional de Educação Matemática. Universidade Federal do Rio de Janeiro (UFRJ). Porto Alegre: UFRJ, 1993.

VERGNAUD, G. A criança, a matemática e a realidade. Tradução de Maria Lucia Faria Moro. Curitiba: Editora UFPR, 2009.

TELES, R. A. M., BELLEMAIN, P. M. B. Fórmulas de área para otimização: um olhar sob a ótica das imbricações entre campos conceituais. Educação Matemática em Revista, São Paulo, v. 31, s.n, p. 4-13, 2013.

TINOCO, L. A. A. Construindo o conceito de Função. IM-UFRJ. Projeto FundãoSPEC/PADCT/CAPES. Rio de Janeiro: Projeto Fundão, 2002.

TINOCO, L. et al. Caminhos da álgebra na escola básica. In: SEMINÁRIO DE PESQUISA EM EDUCAÇÃO MATEMÁTICA DO ESTADO DO RIO DE JANEIRO, 6, 2008, Rio de Janeiro. Anais... Rio de Janeiro. 2008. s.p.

Recebido em: 07 de dezembro de 2018.

Aceito em: 14 de dezembro de 2018. 